\title{
Appropriateness of admissions of children with cancer to intensive care facilities in a resource-limited setting
}

\begin{tabular}{|c|c|}
\hline \multicolumn{2}{|c|}{$\begin{array}{l}\text { Authors: } \\
\text { Nadia Beringer }^{1,2} \\
\text { Janet E. Poole } \\
\text { Daynia E. Ballot } \\
\text { Jennifer A. Geel } \\
\text { Jen }\end{array}$} \\
\hline $\begin{array}{l}\text { Affiliations: } \\
{ }^{1} \text { Division of } \mathrm{Pa} \\
\text { Haematology } \\
\text { Charlotte Max } \\
\text { Johannesburg } \\
\text { Hospital, Sout }\end{array}$ & $\begin{array}{l}\text { ediatric } \\
\text { and Oncology, } \\
\text { eke } \\
\text { Academic } \\
\text { h Africa }\end{array}$ \\
\hline \multicolumn{2}{|c|}{$\begin{array}{l}{ }^{2} \text { Department of Paediatrics } \\
\text { and Child Health, Faculty of } \\
\text { Health Sciences, University } \\
\text { of the Witwatersrand, } \\
\text { South Africa }\end{array}$} \\
\hline \multicolumn{2}{|c|}{$\begin{array}{l}{ }^{3} \text { Division of Neonatology and } \\
\text { Paediatric Intensive Care, } \\
\text { Faculty of Health Sciences, } \\
\text { University of the } \\
\text { Witwatersrand, South Africa }\end{array}$} \\
\hline \multicolumn{2}{|c|}{$\begin{array}{l}\text { Corresponding author: } \\
\text { Nadia Beringer, } \\
\text { nadia.beringer@gmail.com }\end{array}$} \\
\hline $\begin{array}{l}\text { Dates: } \\
\text { Received: } 08 \mathrm{~J} \\
\text { Accepted: } 09 \\
\text { Published: } 28\end{array}$ & $\begin{array}{l}\text { uly } 2017 \\
\text { Aug. } 2017 \\
\text { Sept. } 2017\end{array}$ \\
\hline \multicolumn{2}{|c|}{$\begin{array}{l}\text { How to cite this article: } \\
\text { Beringer N, Poole JE, Ballot } \\
\text { DE, Geel JA. Appropriateness } \\
\text { of admissions of children } \\
\text { with cancer to intensive care } \\
\text { facilities in a resource-limited } \\
\text { setting. S. Afr. j. oncol. } \\
\text { 2017;1(0), a26. https://doi. } \\
\text { org/10.4102/sajo.v1i0.26 }\end{array}$} \\
\hline \multicolumn{2}{|c|}{$\begin{array}{l}\text { (C) 2017. The Authors. } \\
\text { Licensee: AOSIS. This work } \\
\text { is licensed under the } \\
\text { Creative Commons } \\
\text { Attribution License. }\end{array}$} \\
\hline Read online: & \\
\hline 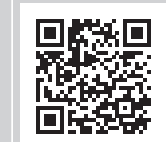 & $\begin{array}{l}\text { Scan this QR } \\
\text { code with your } \\
\text { smart phone or } \\
\text { mobile device } \\
\text { to read online. }\end{array}$ \\
\hline
\end{tabular}

Background: The increasing intensity of treatment of paediatric malignancies has led to improved survival rates, but often necessitates intensive supportive care. The decision to admit a child to the paediatric intensive care unit (PICU) is based on the probability of both short-term and long-term survival in the context of severe resource constraints. Resource constraints in South Africa result in limited access of children with cancer to PICU facilities.

Objectives: The aim of this study was to determine whether referrals by paediatric oncologists to a PICU in Johannesburg were appropriate by analysing indications for admission, underlying diagnoses, duration and costs of admissions, and overall outcomes.

Methods: A retrospective review of consecutive PICU admissions over a 12-year period was performed. Data from all patients with histologically proven malignant conditions were included and analysed using descriptive statistical methods, Kaplan-Meier curves, log-rank analysis and Fisher's exact test.

Results: There were 5704 recorded admissions to PICU in the study period. Of these admissions, $120(2.1 \%)$ were for patients with malignancies. The majority of PICU oncology admissions were for post-operative care, and the median duration of stay was 1 day (interquartile range: 1-3 days). The short-term mortality rate of oncology patients in PICU was $13.3 \%$ in comparison with $16.2 \%$ in the overall PICU population. The 4 -year overall survival rate post PICU discharge was $54 \%$.

Conclusion: The documented short-term mortality rate indicates that referrals by paediatric oncologists are consistent with current PICU admission policies. Oncologists should assess the prognosis for survival before requesting admission to PICU, and, resources permitting, these patients should be accepted to PICU.

\section{Introduction}

The improved survival rates of children diagnosed with cancer in high-income settings are related to advances in treatment modalities as well as access to supportive care. ${ }^{1}$ Patients in upper middleincome countries may have inconsistent access to specialised services, and admission of paediatric oncology patients to paediatric intensive care units (PICUs) is not guaranteed. South Africa has a fragmented, two-tiered health care system based on both privately funded and state-run services. In an attempt to improve equity, a comprehensive National Health Insurance (NHI) plan is envisaged, which will replace the two-tiered model. ${ }^{2}$ The imminent introduction of NHI mandates that specialised services in state hospitals be audited in terms of survival and cost. The aim of NHI is to ensure quality and cost-effective health care for all South Africans in a unified system that obviates the need for a separate privately funded system. ${ }^{2}$ This forthcoming change represents an opportunity for clinicians and health economists to analyse trends in both survival and cost, two essential markers of efficacy of a health care system. ${ }^{3}$

Limited resources dictate that clinicians play a much greater role in decisions involving resource allocation than they might prefer. In well-resourced centres, paediatric intensivists may elect to admit patients who may not have a guaranteed good prognosis. In South Africa, cost constraints necessitate that apart from post-operative patients who generally have a short duration of PICU stay, only patients with a relatively high chance of long-term survival are accepted to PICU. ${ }^{4}$

Charlotte Maxeke Johannesburg Academic Hospital (CMJAH) is a tertiary hospital with a 15 bed PICU. Neonates and children requiring medical and surgical intensive care are all admitted 
to this unit. This PICU services a large part of the southern Gauteng Province and admits approximately 530 patients for admission per year, including indigent patients, partially funded patients and those with medical insurance, although this latter group is in the minority. In the setting of urban Johannesburg with insufficient PICU beds for the population, only paediatric patients requiring ventilation are considered potential ICU candidates. The CMJAH paediatric oncology unit accepts children from a large catchment area in South Africa as well as many surrounding African countries. The decision to admit an oncology patient to PICU is largely influenced by the probability of long-term survival or overall survival (OS) in that particular malignancy.

There are no published reports documenting outcomes in South African oncology patients requiring PICU care and few from low- and middle-income settings. ${ }^{5,6}$ As both paediatric oncology and PICU are high cost units, it is apposite to analyse trends and decide whether changes should be implemented. The aim of this study was to determine if oncology admissions to a resource-constrained PICU were appropriate and to analyse short- and long-term survival rates.

\section{Methods}

A retrospective review of consecutive paediatric oncology patients admitted to the PICU at CMJAH between 1 December 2000 and 15 January 2013 was performed. The PICU admissions register was used to identify patients admitted during the study period. Data were cross-checked with the paediatric oncology unit database.

Criteria for admission to PICU in this state hospital were not codified during the study period, and Paediatric Risk of Mortality (PRISM) scores were not routinely calculated. Admission to PICU was based on a reasonable prognosis for both short- and long-term survival, as decided by the senior oncologist and intensivist on duty on an ad hoc basis. Patients alive upon discharge from their PICU admission were classified as short-term survivors. Long-term survival was defined as the overall 4-year survival probability.

Data included patient age, sex, underlying diagnosis, human immunodeficiency virus (HIV) status, indication for admission to the PICU, duration of stay and outcome. This study was limited to patients admitted to this state hospital and did not include those with private funds who were referred to private PICUs, nor did it include those who were referred to this PICU but denied admission, as these records were not available.

A single researcher (N.B.) collated the data to minimise recorder bias. Files with substantially incomplete records were excluded. Descriptive statistical analysis was performed with values of continuous variables with normal distribution presented as mean \pm SD, whereas those with non-normal distribution were recorded as median with ranges. The PICU mortality rate was expressed as number of deaths in PICU divided by the total number of oncology admissions during the study period.

Patients were followed up for at least 4 years from completion of therapy to determine 4-year OS rates. Loss to follow-up, as per study definition, included those patients who discontinued medical follow-up prematurely. They were included in the data analysis using the last date that a medical professional saw them.

Long-term survival probability was calculated using the Kaplan-Meier method with log-rank analysis to determine the impact of sex, underlying diagnosis and indication for admission. Fisher's exact test was calculated to determine if a difference existed between short-term survival rates based on indications for admission to PICU. A $p$ value of 0.05 was considered to be significant.

The cost-to-patient for a single admission to PICU was calculated based on published guidelines for the last year of the study. ${ }^{7}$ The tariff categories for patients seeking health care at South African state hospitals are classified based on their annual income, as depicted in Appendix 1, Table 1-A1. The cost-to-patient ranges from no fee for indigent patients, an agreed upon fee for those funded by medical insurers, to a price comparable to private sector fees for those who are uninsured or not South African citizens (see Appendix 1, Table 1-A2). Costs of services such as blood products and radiology are included in the inpatient fees. The cost-tohospital was not addressed in this study.

Permission to conduct retrospective analysis was obtained from the Human Research Ethics Committee of the University of the Witwatersrand (clearance certificate number M160974).

\section{Results}

There were 5704 recorded admissions to PICU between 1 December 2000 and 15 January 2013. Of these admissions, $120(2.1 \%)$ were for patients with malignancies. In the same period, there were 1071 new oncology patients seen at the CMJAH paediatric oncology unit, with a median of 99.5 (range 81-120) new patients per year. PICU facilities were required in 103 of 1071 paediatric oncology patients $(9.6 \%)$, 13 of whom required two admissions, with two patients being admitted to PICU three times.

\section{Demographics}

Male and female patients were equally represented $(51 \%$ female, $49 \%$ male). The median age at first admission to PICU was 3.8 years (range 1 day to 14.7 years). Four patients (3.9\%) were known to be HIV positive on admission to PICU, 79 patients $(76.7 \%)$ tested HIV negative and 20 patients (19.4\%) had no documented HIV results.

\section{Indications for admission}

The majority $(108 / 120=90 \%)$ of admissions were for postoperative care (see Figure 1), whereas smaller numbers of 


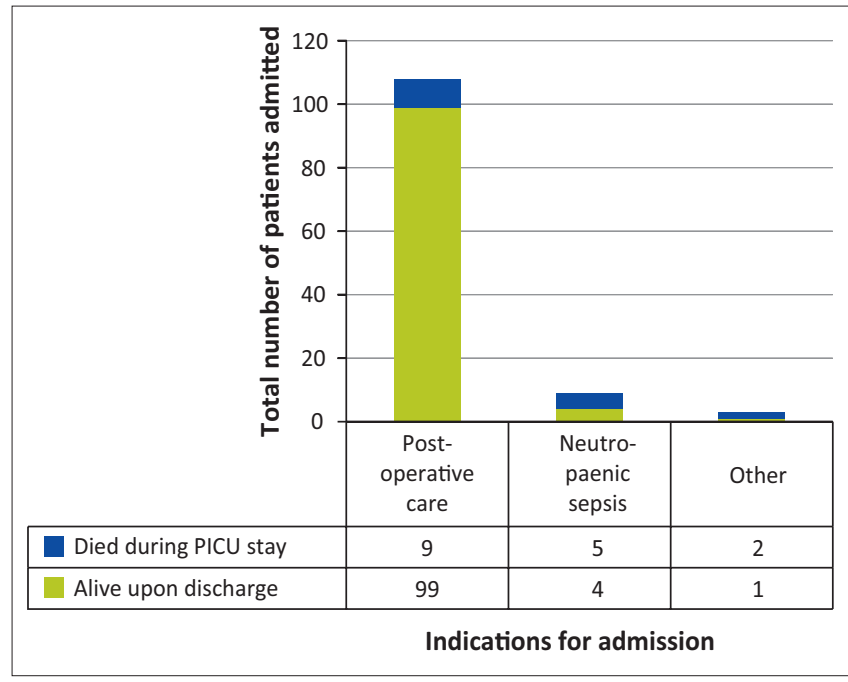

Source: Authors' own work

FIGURE 1: Indications for admission of oncology patients to paediatric intensive care unit.

patients were accepted for management of neutropaenic sepsis $(9 / 120=7.5 \%)$ and other indications $(3 / 120=2.5 \%)$. 'Other' indications included tumour lysis syndrome and complications of the malignancy. Twenty-six patients who were admitted for post-operative care following neurosurgical procedures were not referred to the paediatric oncology unit; therefore, detailed information about these patients was not available.

\section{Primary oncological diagnoses}

The underlying malignant categories were central nervous system in 49 patients $(47.6 \%)$, solid tumours in 37 patients (35.9\%), haematolymphoid malignancies in 7 patients $(6.8 \%)$ and other malignancies in 10 patients (9.7\%) (see Figure 2). Other malignancies included phaechromocytomas, adrenocorticoid carcinomas, haemangioblastomas and nasopharyngiomas.

\section{Mortality in paediatric intensive care unit}

The in-hospital mortality rate of oncology patients in PICU was $13.3 \%$. The overall PICU mortality rate at CMJAH for all patients older than 1 month admitted to PICU for 2013-2015 was 16.2\%. ${ }^{8}$ Causes of death in the oncology patients admitted to PICU included sepsisrelated complications in 5 patients, disease (malignancy) in 4 , treatment complications (treatment-related mortality) in 4 patients and other causes (not clearly specified) in 3 patients (see Figure 3).

\section{Short- and long-term survival rates}

The short-term survival rate of patients admitted for neutropaenic sepsis was $4 / 9(44.4 \%)$, post-operative patients 99/108 (91.7\%) and 'other' 1/3 (33.3\%). The observed difference in short-term survival between patients admitted for neutropaenic sepsis and those

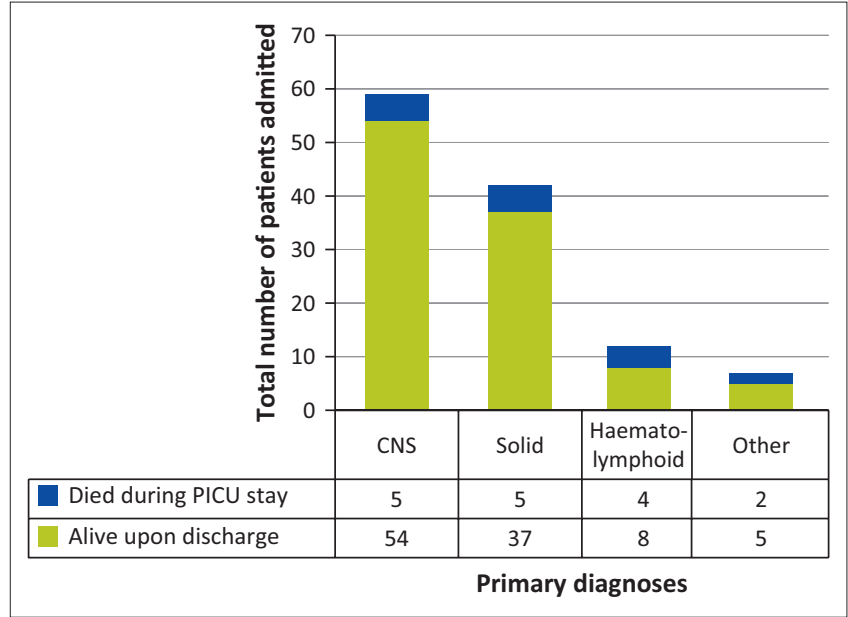

Source: Authors' own work

FIGURE 2: Primary diagnoses of oncology patients admitted to paediatric intensive care unit.

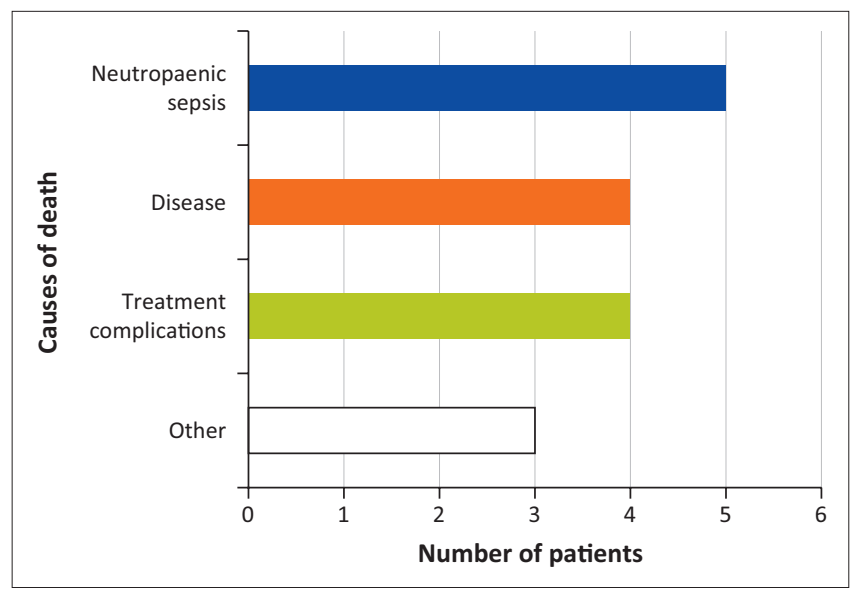

Source: Authors' own work

FIGURE 3: Causes of death during paediatric intensive care unit admission.

TABLE 1: Short-term and long-term survival based on indications for paediatric intensive care unit admission.

\begin{tabular}{lcc}
\hline $\begin{array}{l}\text { Indication for } \\
\text { admission }\end{array}$ & $\begin{array}{c}\text { Short-term } \\
\text { survival rate }\end{array}$ & $\begin{array}{c}\text { Three year overall } \\
\text { survival probability by } \\
\text { Kaplan-Meier analysis }\end{array}$ \\
\hline Post-operative & $92.6 \%$ & $55.7 \%$ \\
Neutropaenic sepsis & $44.4 \%$ & $44.4 \%$ \\
Other & $33.3 \%$ & $33.3 \%$ \\
Fisher's exact test & $p<0.0003$ & - \\
Odds ratio & $15.6(\mathrm{Cl} 3.5$ to 70.0$)$ & - \\
Log-rank test & - & $p=0.200$ \\
\hline
\end{tabular}

Source: Authors' own work

admitted for post-operative care was statistically significant $(p<0.0003)$ with an odds ratio (OR) of 15.6 (CI 3.5 to 70.0$)$ (see Table 1).

Kaplan-Meier survival analysis of the entire cohort demonstrated a 4-year OS probability of $53.5 \%$, with no evidence of difference in long-term survival rates associated with underlying malignancy type or indication for admission (see Figure 4). Log-rank hypothesis testing demonstrated no influence on long-term survival of $\operatorname{sex}(p=0.29)$ and underlying malignancy type $(p=0.09)$. 


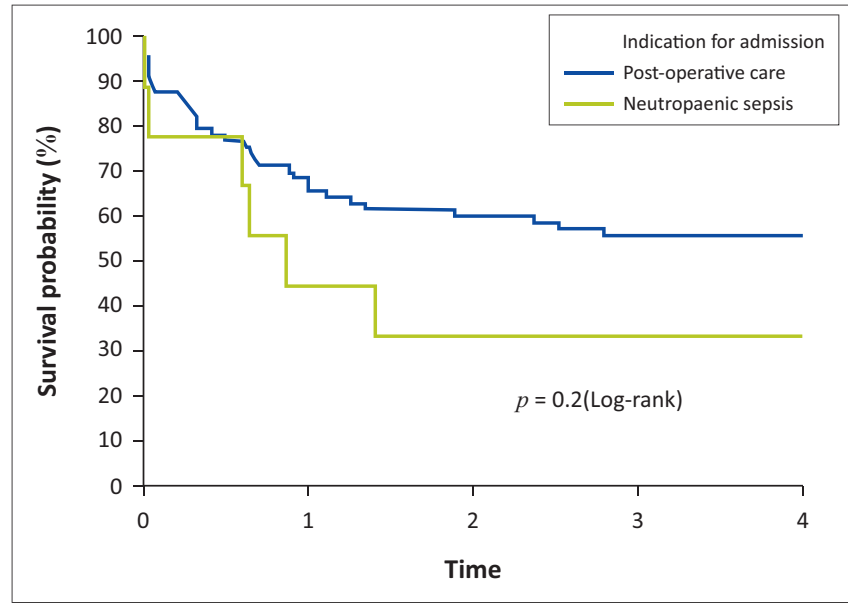

Source: Authors' own work

FIGURE 4: Survival probability according to indication for admission.

\section{Duration and cost of stay}

The median duration of PICU admission was 1 day (interquartile range 1-3 days). The cost-to-patient for an admission to PICU was calculated based on figures published in the Provincial Gazette Extraordinary 2013.7 The maximum fee for the median duration of admission was R7520 for self-funded and foreign patients (see Appendix 1, Table 1-A1 and Table 1-A2.)

\section{Discussion}

During the study period, oncology admissions to PICU were infrequent, and the majority were admitted for postoperative care. The median duration of stay in PICU was 1 day, representing a low median expenditure per patient.

The mortality rate for all paediatric oncology patients accepted for admission to PICU was slightly lower than the mortality rate for all children in PICU.

Central nervous system tumours were the underlying diagnoses in almost half of the study patients with excellent short-term survival rates. A third of the patients with haematolymphoid tumours as their underlying oncological diagnosis died before PICU discharge. Patients admitted with neutropaenic sepsis demonstrated poor short-term survival rates and were 15 times more likely to die than their peers admitted for post-operative care.

Four-year OS probability showed no difference in long-term survival rates associated with underlying malignancy type or indication for PICU admission; however, the numbers in this study were small.

Advances in the development and use of chemotherapy have led to a dramatic improvement in the survival of patients with childhood cancers over the last five decades.9,10,11 Today, children diagnosed with cancer have a projected survival rate of approximately $80 \%$ in high-income countries ${ }^{11,12}$ in comparison with the published OS rate of $52.1 \%$ in middleincome South Africa. ${ }^{9}$ The number of oncology patients requiring admission to the PICU has increased, reaching up to $40 \%{ }^{12}$ of patients during the course of their disease in both low- and high-income centres. . $, 11,13,14$ These children often have severe myelo- and immunosuppression and are more likely than other paediatric patients to require PICU care.,14 Timely recognition and early PICU admission offer opportunities to prevent and manage life-threatening complications of cancer management. ${ }^{15}$

In the study, oncology admissions comprised $2.1 \%$ of all PICU admissions. This is in keeping with previously published literature which state that paediatric oncology patients account for approximately $3 \%$ of PICU admissions. ${ }^{10,12}$ Small admission numbers are seen in upper middle-income countries (UMIC) and lower middle-income countries (LMIC) alike. ${ }^{6,13,16}$ In low- or middle-income countries, the strict criteria for admission to PICU, dictated by resource constraints, result in a small number of oncology patients being timeously admitted. These admissions cause substantial physical, emotional and financial burdens in resource-limited settings. ${ }^{13}$ The cost-to-hospital for the majority of uninsured patients, while not assessed here, necessitates that these facilities be appropriately utilised, ensuring that each potential PICU candidate is stringently evaluated and the survival potential for admission as well as long-term outcome determined.

As the cost-to-patient for this admission depends largely on hospital classification (see Appendix 1, Table 1-A1), an indigent patient paid no fee, being fully subsidised by the state, whereas a patient whose family income was not enough to afford medical insurance, but too high to qualify for subsidised care, was liable for the amount of R7520 for 1 day. The average South African household income for 2013 (last year of study) was approximately R14 720 per month with a national unemployment rate of $24.9 \%{ }^{17}$ The cost of a PICU admission may be prohibitive for families with limited funds who do not qualify for fully subsidised care. Thus, each case must be individualised, taking into account available funds, funds already spent and the short- and long-term prognosis of the child.

Demographic assessment revealed a high number of patients with unknown HIV status. These patients were referred to PICU in extremis and died before testing, or were patients who were admitted to PICU via a surgical discipline and not referred to the oncology unit, and thus did not have routine HIV tests performed.

Central nervous system tumours were the most common underlying oncological diagnoses in the study and had the best short-term outcome upon discharge from PICU. This reflected the fact that most of these patients were admitted electively for post-operative monitoring and care. However, the long-term quality of life and functional status of these patients were not assessed in this study. Comparable studies revealed haematolymphoid tumours to be the most common primary oncological diagnosis in patients requiring PICU care. ${ }^{11,13,16}$ Thus, the study finding seemingly contradicts previously published literature and may reflect the CMJAH PICU 
admission practice of admitting only those patients requiring ventilation and not those requiring a high-care setting. Thus, the paediatric oncology patients who may have benefited from PICU support but who did not require ventilatory support were not considered as potential PICU candidates in accordance with hospital policy. There was no available data on the number of these patients, as these records were not kept.

Mortality risk prediction is often more challenging in children with cancer than other PICU candidates as they experience an acute life-threatening event superimposed on a chronic condition. ${ }^{6,11}$ Maintaining low mortality rates for children with cancer in PICU requires clear clinical guidelines and stringent admission criteria. Systems such as the PRISM III have limited prognostic value when used in the paediatric cancer patient. Such systems were not developed for this specific cohort and often lead to incorrect predictions, either over- or under-predicting mortality., ${ }^{5,10,11}$ These scores were not assessed in this study.

When compared to results from both well (18\%) and poorly resourced (33\%) centres, the mortality rate in this study is substantially lower than the rates described in studies worldwide, ${ }^{13,17,18}$ but a selection bias was created with the exclusion of patients with poor underlying prognoses in this study.

Higher mortality rates in oncology patients compared with general paediatric patients in a PICU setting are well documented,$^{10}$ and risk factors associated with poor survival include the combined use of mechanical ventilation and inotropic support, and the presence of multi-organ failure. ${ }^{14}$ In contrast with earlier studies, Keengwe et al. in 1999 documented a marked improvement in survival of oncology patients admitted to the PICU in a United Kingdom Children's Hospital, especially those with either systemic or respiratory infection needing ventilation. ${ }^{14}$ However, in this study, patients with neutropaenic sepsis demonstrated poor short-term survival rates. The number of neutropaenic patients in this subgroup was small and not representative of the total number of oncology patients requiring PICU (those who were denied admission to PICU during the study). These results must therefore be interpreted with caution.

In the study, only patients who required ventilation were potential PICU candidates. Neutropaenic patients, therefore, have failure of two or more organs at the time of PICU admission (myelosuppression and respiratory failure), thus decreasing their chances of survival. At CMJAH, some of these patients are then treated with inotropes in the oncology ward with a degree of success, but, again, records have not been kept to audit this practice.

Permissive PICU admission policies with early and aggressive treatment may be beneficial to oncology patients. ${ }^{15}$ Such policies advocate rapid and comprehensive initiation of treatment which is followed by a defined treatment phase in PICU. ${ }^{19}$ This approach is currently not feasible in the resourceconstrained South African setting, but may have merit in better resourced settings. Ballot et al. described an imbalance between the numbers of paediatric patients requiring PICU and the availability of PICU facilities in Johannesburg, concluding that patients should be carefully selected to utilise these scarce resources to the best advantage. ${ }^{20}$

The 4-year OS rate of paediatric oncology patients who survive a PICU admission in this study, while low, is no worse than the published 4-year OS for all oncology patients in South Africa ${ }^{9}$ and suggests that these patients should not be denied admission to PICU based on their underlying diagnosis. It is imperative that oncologists select PICU candidates with a good projected chance of survival and continue to communicate closely with intensivists. At this stage, resources constraints do not allow for increased access to PICU facilities in the state hospital sector, but we recommend continued advocacy for improved supportive care for children with cancer.

\section{Conclusions}

There is a high cost involved in PICU admissions, and limited resources have resulted in insufficient PICU beds for a growing population. However, this study has demonstrated that oncology patients admitted to a Johannesburg PICU have a low short-term mortality rate and a short median duration of stay.

Of necessity, clinicians in such settings will continue to take responsibility for allocation of scarce resources. Clear PICU admission criteria should be devised and widely distributed, and a threshold for admission should be established. Other factors such as septic shock, requirement for inotropic support and mechanical ventilation should also be taken into account when assessing risk as these are known to predict poorer outcomes. Oncologists should make a measured assessment of the chances of survival before requesting admission to PICU, and these patients should be accepted to PICU if there are beds available. Close communication between the two specialised teams is essential, as is ongoing auditing of outcomes.

Future avenues for research include prospective studies assessing the role of comorbidities such as HIV and malnutrition, intensity of chemotherapy and radiation as well as PICU admission PRISM scores on both short- and long-term outcomes. Larger, multi-centre studies are required to answer many of the questions explored here with more accuracy. The cost-to-hospital of a PICU admission should also be determined. We recommend the creation of a list of clear PICU admission criteria.

Increased PICU support and more inclusive PICU admission policies will undoubtedly improve the childhood cancer survival rates in low- and middle-income countries.

\section{Acknowledgements}

The authors would like to thank Mrs Susanna Kriel, CMJAH paediatric oncology secretary. 


\section{Competing interests}

The authors declare that they have no financial or personal relationships that may have inappropriately influenced them in writing this article.

\section{Authors' contributions}

All authors have contributed to the manuscript significantly; they have reviewed and agreed upon the manuscript content.

J.A.G. conceptualised the study. N.B. was the project leader. N.B. and J.A.G. collected and collated the data. N.B., J.A.G. and D.E.B. analysed the data. D.E.B. and J.E.P. approved the manuscript.

\section{References}

1. Owens C, Mannion D, O'Marcaigh A, Waldron M, Butler K, O'Meara A. Indications for admission, treatment and improved outcome of paediatric haematology/ oncology patients admitted to a tertiary paediatric ICU. Ir J Med Sci. 2011;180(1):85-89. https://doi.org/10.1007/s11845-010-0634-8

2. Department of Health (South Africa), National Health Insurance in South Africa policy paper [homepage on the Internet]. 2011 [cited 2016 Feb 01]. Available from: http://www.gov.za/sites/www.gov.za/files/nationalhealthinsurance.pdf

3. Krousel-Wood MA. Practical considerations in the measurement of outcomes in healthcare. Ochsner J 1999;1(4):187-194.

4. Argent AC, Ahrens J, Morrow BM, et al. Pediatric intensive care in South Africa: An account of making optimum use of limited resources at the Red Cross War Memorial Children's Hospital. Pediatr Crit Care Med. 2014;15(1):7-14. https:// doi.org/10.1097/PCC.0000000000000029

5. Zinter MS, DuBois SG, Spicer A, Matthay K, Sapru A. Pediatric cancer type predicts infection rate, need for critical care intervention, and mortality in the pediatric intensive care unit. Intensive Care Med. 2014;40(10):1536-1544. https://doi. org/10.1007/s00134-014-3389-2

6. Akhtar N, Fadoo Z, Panju S, Haque A. Outcome and prognostic factors seen in pediatric oncology patients admitted in PICU of a developing country. Indian Pediatr. 2011;78(8):969-972. https://doi.org/10.1007/s12098-011-0391-3
7. Gauteng (South Africa). 2013. Hospital classifications, tariff classifications and relevant costs to patient. Gauteng Provincial Gazette No. 87:19, 8 Apr. Johannesburg: Publication of the Gauteng Provincial Administrator.

8. Ballot DE, Davies VA, Cooper PA, Chirwa T, Argent A, Mer M. Retrospective crosssectional review of survival rates in critically ill children admitted to a combined paediatric/neonatal intensive care unit in Johannesburg South Africa, 20132015. BMJ Open. 2016;6:e010850:1-7. https://doi.org/10.1135/bmjopen-2015010850

9. Stones DK, De Bruin GP, Esterhuizen TM, Stefan DC. Childhood cancer survival rates in two South African units. S Afr Med J. 2014;104(7):501-504. https://doi. org/10.7196/SAMJ.7882

10. Demaret P, Pettersen G, Hubert P, Teira P, Emeriaud G. The critically ill pediatric hemato-oncology patient: Epidemiology, management, and strategy of transfer to the pediatric intensive care unit. Ann Intensive Care 2012;2(14):1-13. https://doi. org/10.1186/2110-5820-2-14

11. Meyer S, Gottschling S, Biran T, et al. Assessing the risk of mortality in paediatric cancer patients admitted to the paediatric intensive care unit: A novel risk score? Eur J Pediatr. 2005;164(9):563-567. https://doi.org/10.1007/s00431-005-1695-y

12. Piastra M, Fognani G, Franceschi A. ICARO Italian Network for Intensive Care in Pediatric Oncology. Pediatric intensive care unit admission criteria for haematooncological patients: A basis for clinical guidelines implementation. Pediatr Rep. 2011;3(e13):42-44. https://doi.org/10.4081/pr.2011.e13

13. Heney D, Lewis IJ, Lockwood L, Cohen AT, Bailey CC. The intensive care unit in paediatric oncology. Arch Dis Child. 1992;67(3):294-298. https://doi.org/ 1010.1136/adc.67.3.294

14. Keengwe IN, Stansfield F, Eden OB, Nelhans ND, Dearlove OR, Sharples A Paediatric oncology and intensive care treatments: Changing trends. Arch Dis Child. 1999;80(6):553-555. https://doi.org/10.1136/adc.80.6.553

15. Azoulay E, Soares M, Darmon M, Benoit D, Pastores S, Afessa B. Intensive care of the cancer patient: Recent achievements and remaining challenges. Ann Intensive Care. 2011;1(1):5. https://doi.org/10.1186/2110-5820-1-5

16. Rosenman MB, Vik T, Hui SL, Breitfeld PP. Hospital resource utilization in childhood cancer. J Pediatr Hematol Oncol. 2005;27(6):295-300. https://doi.org/10.1097/01. mph.0000168724.19025.a4

17. Trading Economics, South Africa average monthly gross wage 2013 [homepage on the Internet]. 2016 [cited 2016 Dec 06]. Available from: http://www. tradingeconomics.com/south-africa/wages.

18. Childhood and Cancer: Children's Health and the environment [homepage on the Internet]. 2009 [cited 2017 Jan 25]. Available from: www.who.int/ceh/capacity/ cancer.pdf.

19. Von Bergwelt-Baildon M, Hallek MJ, Shimabukuro-Vornhagen AA, Kochanek M. CCC meets ICU: Redefining the role of critical care of cancer patients. BMC Cancer. 2010;10:612. https://doi.org/10.1186/1471-2407-10-612

20. Ballot DE, Davies VA, Rothberg AD, Ginsberg N. Selection of paediatric patients for intensive care. S Afr Med J. 1995;85(11):1221-1226. 


\section{Appendix 1}

TABLE 1-A1: Financial classification codes. ${ }^{7}$

\begin{tabular}{lll}
\hline Code & Income/assets for individual & Income/assets for family unit \\
\hline H0 & Formally unemployed & - \\
& Social pensioner & Annual income less than $\$ 4230$ \\
H1 & Annual income less than $\$ 3046$ & Assets less than $\$ 19569$ \\
H2 & Assets less than $\$ 12792$ & Annual income $\$ 4230-\$ 8460$ \\
& Annual income $\$ 3046-\$ 6091$ & Assets not more than $\$ 19569-\$ 40042$ \\
H3 & Assets for $\$ 12792-\$ 27157$ & Annual income $\$ 8260$ and more or \\
No medical aid & Annual income $\$ 6091$ and more or & Assets worth more than \\
\hline
\end{tabular}

Source: Gauteng (South Africa) ${ }^{7}$

TABLE 1-A2: Hospital classifications, tariff classifications and relevant costs to patient.

\begin{tabular}{lccc}
\hline Hospital classification (Tariff category) & Inpatient ward Cost (US dollars) & PICU Cost (US dollars) & Median duration 1 day Cost (US dollars) \\
\hline H0, HG & 0 per admission & 0 & \$ per 30 days \\
H1 & $\$ 7$ per admission & $\$ 14$ & $\$ 7$ \\
H2 & $\$ 7$ per admission & $\$ 1$ & $\$ 1$ \\
Doctor fee & $\$ 1$ per admission & $\$ 221$ per $12 \mathrm{~h}$ \\
H3 & $\$ 96$ per day & $\$ 8$ per day \\
Doctor fee & $\$ 13$ per day & $\$ 307$ per $12 \mathrm{~h}$ \\
Self-funded, private, foreign & $\$ 135$ per day & $\$ 11$ per $12 \mathrm{~h}$ \\
Doctor fee & $\$ 18$ per day & $\$ 614$
\end{tabular}

Doctor fee

2013: 1 US dollar equalled 11.82 South African Rand (maximum exchange rate).

Rounded off to the nearest dollar. 